\title{
Amitraz poisoning: a lesser known pesticide poisoning
}

\author{
P Gupta ${ }^{*}$ \\ Professor, Safdarjang Hospital and Vardhman Mahavir Medical College, Delhi110034, India.
}

\begin{abstract}
Attempt at suicidal poisoning occur with the intake of any harmful chemical substance available in the vicinity of the victim. Amitraz is an ectoparasite repellant and insecticide used inagriculture and veterinary medicine. Amitraz poisoning is unusual, may be associated with severe symptoms. Amitraz intake is rarely lethal and management is symptomatic. We report a case of a suicidal attempt with ingestion of $15 \mathrm{ml}$ of $12.5 \%$ amitraz by a 34-year old youth. He was found in a state of unconsciousness. He had miosis, persistent bradycardia and severe hypotension. The patient was managed symptomatically and was discharged in good health over the next 36 hours.
\end{abstract}

Keywords: Amitraz poisoning; symptomatic treatment

\section{Introduction}

Amitraz is a formamidine pesticide widely used in agriculture and veterinary medicine as an insecticide and acaricide. ${ }^{1}$ Cases of human poisoning with amitraz are extremely rare in the literature. The reported effects of amitraz intake may include CNS depression, hypothermia, bradycardia, hypotension, hyperglycemia, glycosuria, vomiting and respiratory failure. ${ }^{2}$

We report a case of suicidal poisoning with amitraz which was successfully managed on symptomatic guidelines.

\section{Case report}

A 34 years old male was brought to the emergency department in an unconscious state almost one hour after self-ingestion of pesticide amitraz. His relatives had informed that the patient had three episodes of vomiting and recovered an empty bottle of amitraz $12.5 \%$ in $15 \mathrm{ml}$ formulation. On examination, the patient was unconscious with a Glasgow coma score of $3 / 15$. Pupils were bilaterally constricted and sluggishly reacting to light. Vitals signs revealed a heart rate of 42 beats/min, unrecordable blood

\footnotetext{
*Correspondence: P Gupta

E mail: p.gupta182@gmail.com

iD https://orcid.org/0000-0002-3075-3412

Received: $14 / 07 / 2017$

Accepted: 09/10/2017

DOI: http://doi.org/10.4038/slja.v26i1.8265
}

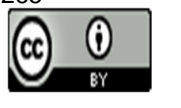

pressure, shallow breathing with a respiratory rate of $8-12 / \mathrm{min}$ and oxygen saturation $\left(\mathrm{SpO}_{2}\right)$ of $90 \%$ on $6 \mathrm{~L} / \mathrm{min}$ of oxygen via facemask. Examination of other systems were normal. There were no excessive oral secretions or any fasciculations.

Patient was intubated immediately and kept on mechanical ventilation using controlled mode (CMV).

Investigation profile comprising of complete blood count, liver and renal function tests, coagulation profile, serum electrolytes and blood sugar were all within normal limits. Arterial blood gas (ABG) analysis revealed combined respiratory and metabolic acidosis with a $\mathrm{pH}$ of 7.23 which improved progressively in serial $\mathrm{ABG}$ analysis on mechanical ventilation.

As no specific antidote for amitraz poisoning exists, symptomatic treatment comprising of one intravenous bolus of atropine $(1.2 \mathrm{mg})$, Ringer lactate infusion in boluses of $100 \mathrm{ml}$ under CVP monitoring (to a total of $500 \mathrm{ml}$ over one hour) was infused. Dopamine infusion was started at the rate of $10 \mu \mathrm{gms} / \mathrm{kg} / \mathrm{min}$ and titrated to maintain the mean arterial pressure (MAP) of $65 \mathrm{mmHg}$. His blood pressure became normal in 8hours. However, the consistent finding was presence of sinus bradycardia and the heart rate remained between $48-58$ beats/min on continuous ECG monitoring. Initially, patient was unconscious and no sedation was supplemented whilst being on ventilatory support. After $12 \mathrm{hrs}$, patient became agitated, even self-extubated for which he was started on haloperidol $1 \mathrm{mg}$ and promethazine $7.5 \mathrm{mg}$ intravenously. The patient started regaining consciousness with spontaneous 
eye opening and purposeful response to verbal stimuli after $24 \mathrm{hrs}$ of intensive care. The patient was weaned from ventilator, extubated after $32 \mathrm{hrs}$ and shifted to the ward the next day. He was discharged from hospital on the $4^{\text {th }}$ day in good health.

\section{Discussion}

Intoxication with amitraz in adults is usually suicidal and infrequently accidental. Only few reported human intoxications by this pesticide have been cited in literature, the existing information about it has been from animal studies or isolated case reports. Amitraz poisoning occurs via oral, dermal or inhalational routes. The toxic effects of amitraz are due to its $\alpha_{2}-$ adrenergic agonist actions in the central nervous system and both $\alpha_{1}$ and $\alpha_{2}$ adrenergic receptor stimulation in the periphery. It also inhibits monoamine oxidase (MAO) enzyme activity and prostaglandin E2 synthesis. Some of these effects may be dose dependent.It has shown to have rapid toxic effects on both animals and human beings but rarely last beyond 48 hours. ${ }^{3,4,5,6}$

The main clinical presentation is a CNS depressant effect with reduced spontaneous activity, miosis, bradycardia, hypotension, hypothermia, hyperglycemia, and respiratory depression leading to death. If managed early, complete recovery from all signs and symptoms occur in 3-4 days. At lower doses, amitraz toxicity may be manifested by hyper reactivity to external stimuli. ${ }^{7}$

OP poisoning, clonidine, opioids, barbiturates, benzodiazepines, phenothiazines and tricyclic anti-depressants can also mimic similar symptoms and signs in overdose. In most of the reported cases amitraz poisoning, the onset of action ranged between $30-180 \mathrm{~min}$ following ingestion. In our case, patient was found to be conscious by his relative possibly one hourafter ingestion.

Main presenting symptom, in our patient was unconsciousness, respiratory depression, bradycardia and hypotension. Central nervous system depression is predominantly with the effect of amitraz on $\alpha_{2}$-adrenergic receptors. The observation of respiratory depression along with central nervous system depression may suggest a direct inhibitory effect of the agent on the respiratory center. The $\alpha_{1}$ and $\alpha_{2}$ agonistic action of amitraz causes bradycardia and hypotension which were seen in several case reports. ${ }^{8}$

As there is no specific antidote for Amitraz poisoning, the medical management is essentially symptomatic and supportive. ${ }^{6}$ The approach must include haemodynamic stabilization, maintaining airway and measures to reduce absorption of poisonous material. Gastric lavage was performed for our patient, at the time of presentation to the hospital. Dopamine has inotropic and chronotropic effects and in doses of $5-10 \mu \mathrm{g} / \mathrm{kg} / \mathrm{min}$, dopamine stimulates $\beta_{1}$ adrenergic receptors and increases cardiac output by increasing cardiac contractility with variable effects on heart rate. Since only very few case reports on inotrope use in amitraz poisoning are available, convincing data to support any inotrope as the preferred first-line is lacking. To counteract the bradycardia and hypotension caused by amitraz, dopamine in doses of 5-10 $\mu \mathrm{g} / \mathrm{kg} / \mathrm{min}$ as used in our patient, can be the choice of inotrope.

\section{Conclusion}

Despite a life threatening clinical picture involving central nervous system and cardiovascular depression, recovery is usually seen within 12-48h in reported cases of amitraz poisoning in humans and the patients were discharged without any organ dysfunction. It is the previous case reports and review articles that help the physicians in the management as there is a lack of a specific antidote and management protocols.Management of amitraz poisoning is supportive and symptomatic with monitoring of nervous system, cardiovascular and respiratory systems.

\section{Conflict of Interest: None}

\section{References}

1. Orens PG, Zandijk E, Belmans L, Schepens PJ, Bossaert LL. An unusual poisoning with the unusual pesticide amitraz. Hum. Exp. Toxicol 1997;16:600-1.

https://doi.org/10.1177/096032719701601008

PMid:9363478

2. Ulukaya S, Demirag K, Moral AR. Acute amitraz intoxication in human. Intensive Care Med 2001; 27: 930-933. https://doi.org/10.1007/s001340100934 PMid:11430553

3. Prajapati T, Patel N, Zamani N, Mehrpour O. Amitraz Poisoning; A case study. IJPT July 2012;11(2):80-2. 
4. Agin H, Calkavur S, Uzun H, Bak M. Amitraz Poisoning: Clinical and Laboratory Findings. IndianPediatrics2004;41:482-5.

PMid:15181299

5. Aydin K, Per H, Kurtoglu S, Poyrazoglu MH, Narin N, Aslan D. Amitraz poisoning in children. Eur. J Pediatr 2002;161:349-50. https://doi.org/10.1007/s00431-002-0945-5 PMid:12029457

6. Yilmaz HL, Yildizdas DR. Amitraz poisoning, an emerging problem: epidemiology, clinical features, management, and preventive strategies. Arch Dis Child. 2003;88(2):130-4. https://doi.org/10.1136/adc.88.2.130 PMCid:PMC1719437

7. Hasan A, öCalkavuröS, Uzun H, Bak M. Amitraz Poisoning: Clinical and Laboratory Findings. Indian Pediatrics 2004;41: 482-486.

8. Herath HMMTB, Pahalagamage SP, Yogendranathan N, Wijayabandara MDMS et al. Amitraz poisoning: A case report of an unusual pesticide poisoning in Sri Lanka and literature review. BMC Pharmacology and Toxicology. 2017; 18:

1-6.

https://doi.org/10.1186/s40360-016-0114-5

PMid:28110639 PMCid:PMC5256545 